\title{
Development for dolomite national reference materials
}

\author{
Xiangdong WEN ${ }^{1, a}$, Wenyang PAN ${ }^{2, b}$, Qian TAN ${ }^{1, c}$ \\ ${ }^{1}$ Research and Development Center of Wuhan Iron and Steel (Group) Corp., Wuhan, 430080, China \\ ${ }^{2}$ Northwestern Polytechnical University, Xi'an, 710072., China

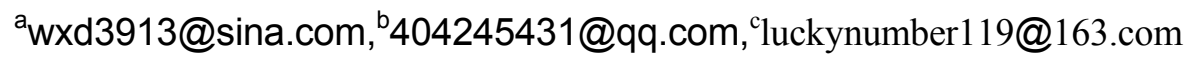

Keywords: dolomite; national standard sample; development

\begin{abstract}
Four dolomite national reference materials has been developed. The whole process including sample composition design, machining, homogenizing examination and standard value analysis have been done according to the requirements of GB/T 15000 《Directives for the work of reference materials》 and $\mathrm{YB} / \mathrm{T} 082$ 《Specification for CRMs for metallurgical product analysis $\rangle$.The calcium oxide contents of reference materials are from $31.49 \%$ to $35.73 \%$, the magnesium oxide contents are from $15.28 \%$ to $21.06 \%$, the silicon dioxide contents are from $0.098 \%$ to $4.21 \%$. The principal components were in a wide range of content while most of the other components changed with the principal component in linear variation which means nearly all of the dolomite varieties has been covered.
\end{abstract}

\section{Introduction}

Dolomite is widely used in producing metallurgical product, building materials, fireproofing refractory matter, chemical materials and so on. In this way, the determination of components content are of great importance, for product quality is directly influenced by it according to different demands of raw material in different industries. Standard sample is a kind of matter that is technical evaluation authorized, provided with exact value and certification, which is a symbol of development of the productive force and scientific progress. Dolomite reference materials are employed in product quality test, apparatus calibration, evaluation of method, unification of observed values, process control as well as evaluation of analysts. GB/T 15000 《Directives for the work of reference materials》 ${ }^{[4]}$ 和 YB/T082 《Specification for CRMs for metallurgical product analysis ${ }^{[5]}$ are performed during the whole development process. The new dolomite national reference materials take advantage in larger range of main components content and linear elementary composition. Varieties of dolomite are adopted in the manufacturing process which will provide with better applicability and more choices when meeting different analytical requirements.

\section{Preparation of reference materials}

Sample component design. The chemical components of dolomite which is used in metallurgy and fireproofing refractory matter is regulated by YB/T 5278-2007. On the base of YB/T 5278-2007, the content range of main components is appropriately expanded, and the contents of $\mathrm{Fe}_{2} \mathrm{O}_{3}, \mathrm{Al}_{2} \mathrm{O}_{3}$, $\mathrm{MnO}, \mathrm{P}, \mathrm{S}, \mathrm{TiO}_{2}$ are designed in a linear distribution as far as possible according to dolomite survey, the principal component contents $(\%)$ of four reference materials design is as follows: $\mathrm{CaO}, \geq 36$ 、 34 36、29 32、32 34; $\mathrm{MgO}, 14 \sim 16 、 16 \sim 18 、 20 \sim 22 、 18 \sim 20 ; \mathrm{SiO}_{2}, 4 \sim 5 、 1 \sim 2 、<0.1$ 、 $<1$.

Sample selection. Sample tracing and testing were carried out in Wulongquan mining company in Wuhan, candidate samples which meet the requirement of component design are chosen through preliminary screening.

Sample processing. According to GB3286-1998《Methods for chemical analysis of limestone and dolomite national standard method $\rangle$, the granularity should be $<0.080 \mathrm{~mm}$, and the process flow is as follows: lump ore_-decontamination_—water scrubbing and drying_- hammer 
crushing_crusher (about $1 \mathrm{~mm})$ efflorescence in ball mill—sieving $(\leq 0.080 \mathrm{~mm})$ 。 oversize efflorescence__ sieving $(\leq 0.080 \mathrm{~mm})$ _blengding_-barreling into clean plastic barrels_bottling.

Pollute test of metallic iron and eliguation test in antigrading process. Iron may slightly be introduced into the sample during the process for the processing equipments, such as crusher, are made of iron, so the samples may be polluted. Ferric chloride leaching-automatic potentiometric titration is used to measure the content of iron in the samples, the weight is $1.0 \mathrm{~g}$ according to the very few content of iron. The test results are all below $0.005 \%$ among the four samples, which reveals that iron which introduced during the process can be ignored totally.

The crushed four samples (granularity $<0.080 \mathrm{~mm}$ ) were put into sample mixer in batches at a speed of $20 \mathrm{r} / \mathrm{min}$ for 7 or 8 hours, then take $10 \mathrm{~g}$ samples from the four inner corner, the center of the roof and the center of the bottom respectively as 6 specimens for eliguation test. Each specimen should be mixed thoroughly before the test. The contents of $\mathrm{SiO} 2, \mathrm{~A} 12 \mathrm{O} 3, \mathrm{MgO}$ and $\mathrm{Fe} 2 \mathrm{O} 3$ are gave by inductively coupled plasma atomic emission spectrometry, the content of $\mathrm{CaO}$ is gave by EDTA compleximetry. The result reveals that the uniformity of each sample is pretty good, the component content is within the scope of permissible error given by national standard analytical method.

\section{Granularity distribution test}

$100 \mathrm{~g}$ sample was sieving into 3 parts: $<0.080 \mathrm{~mm}-0.074 \mathrm{~mm},<0.074 \mathrm{~mm}-0.062 \mathrm{~mm}$ and $<0.062 \mathrm{~mm}$. The content of silicon, aluminum, calcium, magnesium and sulphurin these parts was tested separately. The analytical results showed that there was no obvious eliguation among main components and the components that are easy to be non-uniform in each scope of the particle range in the batch. Thus, when the particle size of reference materials is under $0.080 \mathrm{~mm}$, the uniformity is obtained nicely.

\section{Homogenizing examination}

20 bottles samples were chosen at random to do a spot-check, which were picked in the $2 \sqrt[3]{n}$ sample drawn principle. The main and the easy to be non-uniform components such as $\mathrm{SiO}_{2}$ 、 $\mathrm{CaO} 、 \mathrm{MgO} 、 \mathrm{Al}_{2} \mathrm{O}_{3} 、 \mathrm{Fe}_{2} \mathrm{O}_{3} 、 \mathrm{MnO} 、 \mathrm{~S} 、 \mathrm{P} 、 \mathrm{~K}_{2} \mathrm{O}$ was tested by X-ray fluorescence spectrometry after squashed (minimum weight is $0.2 \mathrm{~g}$ ) and gravimetric method(loss on ignition, the weight is $1.0000 \mathrm{~g}$ ) in purpose of homogenizing examination. 3 specimens were taken from each bottle, testing in random number, 60 specimens in total.

The mathematical statistics of homogenizing examination is taken in one-factor analysis of variance. The specific method is as follows: According to DOF(degree of freedom) and given significance level $\alpha$, the $\mathrm{F} \alpha$ can be obtained from Table $\mathrm{F}$. When $\mathrm{F}<\mathrm{F} \alpha$, the sample is non-uniform. When $\mathrm{F}>\mathrm{F} \alpha$, the sample is uniform. The $\mathrm{F}$ test values of the 10 components of the 4 samples are in the scope of 0.75 to 1.76 , all of which are below the critical value 1.85 (F0.05), in this way, the homogeneity of this batch perfectly meets the homogeneity requirements of reference materials. The value of the uncertainty part which is introduced by non-uniformity is from $1.98 \times 10-5$ to 0.042 .

\section{Value determination}

1)Analytical method of value determination.9 laboratory engaged in the value determination of 13 components such as $\mathrm{SiO}_{2} 、 \mathrm{CaO} 、 \mathrm{MgO} 、 \mathrm{Al}_{2} \mathrm{O}_{3} 、 \mathrm{Fe}_{2} \mathrm{O}_{3} 、 \mathrm{MnO} 、 \mathrm{P} 、 \mathrm{~S} 、$ loss in ignition and so on. The detailed analytical method is shown in table 1.

Table1 Analysis method of every component fixed value

\begin{tabular}{|c|l|c|}
\hline Component & Analytical method & No. of laboratory \\
\hline $\mathrm{SiO}_{2}$ & Silicomolybdic blue spectrophotometric & 7 \\
\hline
\end{tabular}




\begin{tabular}{|c|c|c|}
\hline & Perchloric acid dehydration gravimetric method & 7 \\
\hline & Inductively coupled plasma atomic emission spectrometry & 2 \\
\hline \multirow{2}{*}{$\mathrm{CaO}$} & EDTA compleximetry GB/T 3286.1-1998 & 8 \\
\hline & EGTA-CyDTA compleximetry GB/T 3286.1-1998 & 1 \\
\hline \multirow{2}{*}{$\mathrm{MgO}$} & EDTA compleximetry & 8 \\
\hline & EGTA-CyDTA compleximetry & 1 \\
\hline \multirow{4}{*}{$\mathrm{Al}_{2} \mathrm{O}_{3}$} & Chrome azurol S spectrophotometric method & 6 \\
\hline & Villiaumite replacementEDTA compleximetry & 6 \\
\hline & Sheet melting-X ray fluorescent method & 1 \\
\hline & Inductively coupled plasma atomic emission spectrometry & 2 \\
\hline \multirow{3}{*}{$\mathrm{Fe}_{2} \mathrm{O}_{3}$} & O-phenanthroline spectrophotometric method & 6 \\
\hline & Flame atomic absorption spectrometric method & 2 \\
\hline & Inductively coupled plasma atomic emission spectrometry & 1 \\
\hline \multirow{3}{*}{$\mathrm{MnO}$} & Periodate spectrophotometric method & 2 \\
\hline & Flame atomic absorption spectrometric method & 2 \\
\hline & Inductively coupled plasma atomic emission spectrometry & 5 \\
\hline \multirow{2}{*}{$\mathrm{P}$} & Phosphomolybdate blue spectrophotometric method & 5 \\
\hline & Inductively coupled plasma atomic emission spectrometry & 4 \\
\hline \multirow{2}{*}{$\mathrm{S}$} & Pipe furnace combustion iodic acid potassium titration method & 4 \\
\hline & High frequency combustion with infrared absorption method & 5 \\
\hline L.O.I & Gravimetric methoe & 9 \\
\hline \multirow{2}{*}{$\mathrm{K}_{2} \mathrm{O}$} & Flame atomic absorption spectrometric method & 5 \\
\hline & Inductively coupled plasma atomic emission spectrometry & 4 \\
\hline \multirow{2}{*}{$\mathrm{Na}_{2} \mathrm{O}$} & Flame atomic absorption spectrometric method & 6 \\
\hline & Inductively coupled plasma atomic emission spectrometry & 3 \\
\hline \multirow{2}{*}{$\mathrm{TiO}_{2}$} & Inductively coupled plasma atomic emission spectrometry & 8 \\
\hline & Diantipyrylmethane spectrophotometric method & 1 \\
\hline \multirow{2}{*}{$\mathrm{SrO}$} & Inductively coupled plasma atomic emission spectrometry & 8 \\
\hline & Flame atomic absorption spectrometric method & 1 \\
\hline
\end{tabular}

2)Determination of sulfur in dolomite using high-frequency combustion infrared absorption method.High-frequency combustion infrared absorption method was employed in determination of sulfur in dolomite. Sample must be calcinated under $900-1000^{\circ} \mathrm{C}$ for 1 hour, the sample and flux were added into crucibles like this: $0.2 \mathrm{~g}$ calcinated sample $+0.3 \mathrm{gSn}+0.5 \mathrm{gFe}+1.5 \mathrm{~W}$. Calibration curve was established by samples that are calcinated in the same condition, then determination was carried out following the specification. Sample preparation also can be performed follow GB/T 3286.8-2014, in which the sample is prepared after ignition. The sample and flux are put into the crucible in the same order and amount, then test the sulfur content in the ash follow the instrument specification, finally using the loss in ignition formula to calculate the real sulfur content. This method has been enrolled into the national standard analytical methods, named the methods for chemical analysis of limestone and dolomite-Part 7: The determination of sulfur content.

\section{3)Data from concentration values evaluation and its statistical processing.}

Within-laboratory precision test.Ranges calculated through four data from every lab were less than 1.3 times of laboratory repeatability limit $r$ or otherwise permissible error provided in national standard methods for chemical analysis of limestone and dolomite. For elements not provided in these standards, the data were counted according to permissible error provided in national standard methods for chemical analysis of iron ore, of which ranges also calculated to be less than 1.3r. All the data meet the requirements of within-laboratory precision.

Statistical test of outlier in concentration values evaluation

Outlier could be identified based on Grubbs or Cochran method, and the results showed that there was not any outlier in inter-laboratory data. 
Statistical test of outlier in concentration values evaluation.Outlier could be identified based on Grubbs or Cochran method, and the results showed that there was not any outlier in inter-laboratory data.

Nomal testing of concentration values evaluation. The normality of a new set of data made from average values of with-laboratory data has been verified by Shapiro-Wilk test and test statistics $\mathrm{W}$ has been given. If $\mathrm{W}>\mathrm{W} 0.05$, the data was in normal distribution. All the data got in concentration values evaluation were approved to be in normal distribution except 2\# dolomite sample. W value(0.925) of 2\# dolomite sample was less than W0.05 (0.935) but more than W0.01

(0.912), which means the data was in approximate normal distribution.

Parameters determination in concentration values evaluation. The average value and standard deviation(SD) of a new set of data made from average values of with-laboratory data was calculated to be parameters for concentration values evaluation. Decimals of the SD value needed only round up but not round down when rounding off while the scale stayed the same with the standard values.

Uncertainty evaluation.Uncertainty of reference materials should consist of total standard deviation for sample concentration values evaluation, inter-bottle heterogeneity standard deviation got in homogeneity testing, inter-bottle stable standard deviation got in stable testing. The uncertainty of unstable factors could be ignored since the samples were proved to be stale ${ }^{[7]}$. The standard values, standard deviation, number of test and the expanded uncertainty were shown in Table 2.

Table 2 The standard values of reference materials, standard deviation, number of test and the expanded uncertainty (including factor $\mathrm{k}=2$ )

\begin{tabular}{|c|c|c|c|c|c|c|c|c|}
\hline No. & Item & $\mathrm{SiO}_{2}$ & $\mathrm{CaO}$ & $\mathrm{MgO}$ & $\mathrm{Al}_{2} \mathrm{O} 3$ & $\mathrm{Fe}_{2} \mathrm{O}_{3}$ & $\mathrm{MnO}$ & $\mathrm{P}$ \\
\hline \multirow{4}{*}{$1 \#$} & Standard values $(\%)$ & 4.21 & 35.73 & 15.28 & 0.92 & 0.533 & 0.022 & 0.0032 \\
\hline & Standard deviation & 0.05 & 0.08 & 0.12 & 0.02 & 0.009 & 0.001 & 0.0002 \\
\hline & Expanded uncertainty & 0.04 & 0.06 & 0.09 & 0.02 & 0.007 & 0.001 & 0.0002 \\
\hline & Group number & 9 & 9 & 9 & 9 & 9 & 9 & 9 \\
\hline \multirow{4}{*}{ 2\# } & Standard values $(\%)$ & 1.30 & 34.82 & 17.34 & 0.18 & 0.447 & 0.0072 & 0.0057 \\
\hline & Standard deviation & 0.03 & 0.08 & 0.07 & 0.01 & 0.005 & 0.0005 & 0.0003 \\
\hline & Expanded uncertainty & 0.02 & 0.06 & 0.06 & 0.01 & 0.005 & 0.0003 & 0.0003 \\
\hline & Group number & 9 & 9 & 9 & 9 & 9 & 9 & 9 \\
\hline \multirow{4}{*}{$3 \#$} & Standard values $(\%)$ & 0.098 & 31.49 & 21.06 & 0.083 & 0.024 & 0.0061 & 0.0016 \\
\hline & Standard deviation & 0.004 & 0.06 & 0.06 & 0.003 & 0.002 & 0.0005 & 0.0001 \\
\hline & Expanded uncertainty & 0.003 & 0.05 & 0.05 & 0.002 & 0.002 & 0.0004 & 0.0002 \\
\hline & Group number & 9 & 9 & 9 & 9 & 9 & 9 & 9 \\
\hline \multirow{4}{*}{$4 \#$} & Standard values $(\%)$ & 0.77 & 31.96 & 19.92 & 0.23 & 0.269 & 0.031 & 0.0023 \\
\hline & Standard deviation & 0.03 & 0.09 & 0.07 & 0.01 & 0.004 & 0.001 & 0.0002 \\
\hline & Expanded uncertainty & 0.02 & 0.06 & 0.05 & 0.01 & 0.005 & 0.001 & 0.0002 \\
\hline & Group number & 9 & 9 & 9 & 9 & 9 & 9 & 9 \\
\hline No. & Item & $\mathrm{S}$ & LOI & $\mathrm{Na}_{2} \mathrm{O}$ & $\mathrm{K}_{2} \mathrm{O}$ & $\mathrm{TiO}_{2}$ & $\mathrm{SrO}$ & \\
\hline \multirow{4}{*}{$1 \#$} & Standard values $(\%)$ & 0.029 & 42.69 & 0.015 & 0.017 & 0.042 & 0.031 & \\
\hline & Standard deviation & 0.001 & 0.06 & 0.001 & 0.001 & 0.003 & 0.001 & \\
\hline & Expanded uncertainty & 0.001 & 0.09 & - & 0.001 & - & - & \\
\hline & Group number & 9 & 9 & 9 & 9 & 9 & 9 & \\
\hline \multirow{4}{*}{$2 \#$} & Standard values $(\%)$ & 0.009 & 45.37 & 0.019 & 0.027 & 0.014 & 0.025 & \\
\hline & Standard deviation & 0.001 & 0.08 & 0.001 & 0.001 & 0.002 & 0.001 & \\
\hline & Expanded uncertainty & 0.001 & 0.07 & - & 0.001 & - & - & \\
\hline & Group number & 9 & 9 & 9 & 9 & 9 & 9 & \\
\hline \multirow{3}{*}{$3 \#$} & Standard values $(\%)$ & 0.011 & 46.71 & 0.017 & 0.0030 & 0.0072 & 0.025 & \\
\hline & Standard deviation & 0.001 & 0.10 & 0.001 & 0.0001 & 0.0013 & 0.002 & \\
\hline & Expanded uncertainty & 0.001 & 0.08 & - & 0.0001 & - & - & \\
\hline
\end{tabular}




\begin{tabular}{|l|l|c|c|c|c|c|c|}
\hline & Group number & 9 & 9 & 9 & 9 & 9 & 9 \\
\hline \multirow{5}{*}{$4 \#$} & Standard values (\%) & 0.010 & 46.24 & 0.033 & 0.030 & 0.018 & 0.010 \\
\cline { 2 - 8 } & Standard deviation & 0.001 & 0.09 & 0.001 & 0.001 & 0.002 & 0.001 \\
\cline { 2 - 8 } & Expanded uncertainty & 0.001 & 0.10 & - & 0.01 & - & - \\
\cline { 2 - 8 } & Group number & 9 & 9 & 9 & 9 & 9 & 9 \\
\hline
\end{tabular}

\section{Conclusion}

The batch of dolomite reference materials were with reasonable composition design, sampling and preparation process. The principal component was in a wide range of content while most of the other components changed with the principal component in linear variation which means nearly all of the dolomite varieties has been covered. All four of dolomite standard were proved to be in good homogeneity by composition segregation test, size distribution test and homogeneity test. The standard values were determined from the data got by 9 laboratory using different reliable and correct methods.

\section{References}

[1] Zhang Guang-guo.A brief talk on development and utilization of limestone and dolomite [J].Geological Science and Technology Information.1995(5):1 3.

[2] Li Bao-yin.Chinese nonmetallic mierals Industry Handbook[M].Metallurgical Industry Press, December, 1992.

[3] Quan Hao,etc.Standard materials and its application technology[M] (The second edition) . Beijin: Standard Press of China, 2003.

[4] GB/T15000 Directives for the work of reference materials [S]. Beijin: Standard Press of China. [5] YB/T082-1996 Specification for CRMs for metallurgical product analysis [S ]. Beijin: Standard Press of China, 1997.

[6] YB/T 5278-2007 Dolomite [S] . Beijin: Standard Press of China, 2008.

[7] $\mathrm{Hu}$ Xiao-yan.Evaluation and investigation on the stability of certified reference material[J].Metallurgical Analysis 2000,20(6):31-34. 